\title{
SALTANATIN KALDIRILMASINDAN SONRA ISTANBUL'DA DURUM (FELAH GRUBU RAPORLARINA GÖRE)
}

\author{
Dr. Ayfer ÖZĢLLIKK
}

Bilindiği gibi "Büyük Türk Zaferi" ve arkasından imzalanan Mudanya Mütarekesi'nden sonra Refet (Bele) Paşa TBMM Hükûmeti tarafindan İstanbul ve Trakya Fevkalade Temsilcisi olarak görevlendirildi. Bu sirada Bursa'da bulunan Mustafa Kemal, Fevzi ve İsmet Paşalarla burada görüşen ve İstanbul'da takip edeceği hareket hakkında talimat alan Refet Paşa ${ }^{1} 19$ Ekim 1922'de İstanbul'a geldi. O'nun İstanbul'a gelişi olağanüstü bir hadise olmuş ve onbinlerce kişinin katıldığı büyük bir törenle kurtarıcı gibi karşılanmıştır. Aslında bu karşılanma yıllardan beri kendi topraklarında ezik, silik ve baskı içinde yaşayan Türklerin hem kurtuluşa hem de TBMM Hükûmeti'nin İstanbul'da da yerleşmesine duyulan șevincin ifadesi idi²

Refet Paşa aldığı talimat gereği daha ilk günden itibaren şahsî saltanatın ortadan kalktığını, Osmanlı Ailesi'nin dinî bir otorite olmaktan başka bir güce sahip olamayacağını açıkca hissettiren beyanatlar veriyordu. Özellikle O'nun "Saltanat-1 Millîye" tabiri saray ve çevresinde endişe ve telaşla karşılanmışt ${ }^{3}$. Bu durumda İstanbul'da mevcut siyasî durumun değişeceği beklenmekte, fakat bu değişikliğin boyutları hakkında kesin bir yargıya varılamamaktaydı.

Refet Paşa'nın İstanbul'daki faaliyetleri devam ederken Mustafa Kemal ve başlattıği Millî Hareket'in başından beri muhaliflerinden olan Ali Kemal Bey, tutuklanmış ve halk tarafindan linç edilmiştir ${ }^{4}$. $\mathrm{Bu}$ olay gerek saray ve gerekse diğer muhalif çevreler üzerinde şok etkisi yaratmıştı. VI. Mehmet Vahidettin. TBMM'nin kendisi hakkında bundan sonrası için düşündüklerini en yetkili ağızdan öğrenmek amacıyla Refet Paşa'yı 29 Ekim 1922 tarihinde görüşmeye çağırdı. Görüşme sırasında Refet Paşa artık fiilen gereği kalmayan İstanbul

I Ali Fuat CEBESOY, Siyasî Hatıraları I. Kısım, İstanbul 1957, s. 102

2 Paul GEnTizon, Mustafa Kemal ve Uyanan Doğu (Çev. Suphi Nuri Ileri), Ankara, 1983, s. 23-24

3 Cebesoy, a.g.e., s. 108

4 Gentizon, a.g.e., s. $27-29$ 
Hükümeti'ni dağıtmasını Vahidettin'den istemiş ve aldığı red cevabı üzerine, TBMM ve Hükûmet üyelerinin kendisinin düşmanlarla işbirliği yaptığı düşüncesini taşıdıklarını ve bu yüzden kendisine karşı olduklarını, belki halifelik makamında bile bırakılmayacağını ihtar etmiştir ${ }^{5}$.

Aynı gün, 29 Ekim 1922'de Tevfik Paşa'nın BMM Riyeseti'ne hitaben yazdığı ikinci telgrafi alınmış ve Meclis'te esash bir muhalefetle karşılaşılmadan 1 Kasım 1922 tarihli kanunla saltanat kaldırılmıştır ${ }^{6}$. Aynı kanuna göre BMM Osmanlı Ailesi'nden en uygun gördüğü şahsı halife seçecekti. Bu durumda hilafet kesin ve net bir hukuki durum tayin edilmeden bir süre daha bırakılıyor, halifenin kim olduğu veya kimin olacağı hakkında hiç bir açıklama yapılmıyordu?

Bundan sonra gerek saray ve çevresinde gerek muhalif gruplar üzerinde tam bir kararsızlık ve kargaşanın hakim olduğu anlaşılmaktadır. BMM'nin kararını öğrendikten sonra toplanan İstanbul Kabinesi önce bir neticeye varamadan dağılmış ise de 4 Kasım 1922'de tekrar toplanarak istifa etmiştir". Bu kabine toplantılarının ilki "huzurda", ikincisi ise Bab-1 Ali'de yapılmışır ${ }^{9}$. Gerek saltanatın ilgasına ait karar ve gerekse Tevfik Paşa Hükumeti'nin istifası üzerine İstanbul'daki başta Jandarma Kumandanı, Polis Müdürü ve Belediye Başkanı olduğu halde, bütün askerî ve sivil erkan Refet Paşa'ya gelerek, Ankara'ya bağllıklarını bildirmeleri Vahidettin'in durumunu daha da karmaşı bir hale getirmişti ${ }^{10}$.

İstanbul'dan alınan istihbarat raporlarından anlaşıldığına göre, saltanatin ilgasindan hemen sonra sarayda hanedan mensuplar1 arasında devamlı toplantılar yapılmaya başlanmışır. Ayrıca Sarayla Ingiliz ve Fransız temsilcilerinin görüşmelerinin sıklaştığı da anlaşılmaktadır. Vahidettin'in kaçı̧ına kadar sıkça tekrarlanan bu gö-

5 Gentizon, a.g.e., s. 27-29. Bu görüșme sırasınida Refet Paşa selamlık resmi dışında padişahın dışarı çıkmamasını ve sạrayda da kimseyle görüşmemesini söylemiştir (İbnülemin Mahmut Kemal INAL, Son Sadrazamlar, 4. Cilt, s. 2097-2098). Felah Grubu 29.10.1922 tarihinde gönderdiği raporda Refet Paşa'nın saraya giderek Vahidettin ile 2. 5 saat görüştüğünü ve Harbiye Nazırı Ziya Pașa'nın İstanbul Kabinesi tarafından Ankara'ya görüşsmek üzere gönderileceğini haber verirken, 2 Kasım'da da Fevzi Paşa, Refet Paşa'dan görüşme hakkında kendilerine hilgi verilmesini istiyordu (ATASE Arsiv 1/4283, Kl., 1684, Dos,. $39(436)$, Fh. 6, 6-1)

6 Nutuk C. II, İst. 1981, s. 691 vd.; Cebesoy, a.g.e., s. 132:, İbnülemin, a.g.e., s. 1742.

7 M. Kamran ARDAKOC,, Hilafet Meselesi, Ist. 1955, s. 11

8 ATASE Arșiv 1/4283, Kl. 1684, Dos. 39 (436), Fh. 9-11; İbnülemin, a.g.e., s. 1742

9 İbnülemin, a.g.e., s' 1742.

10 Cebesoy, a.g.e., s. 134 
rüşmelerde İngilizlerin O'na BMM'nin kararını kabul etmemesi ve gerekirse Britanya Hükûmeti'nin yardım edeceği teminatının verildiği anlaşılmaktadır. ${ }^{11}$.

Ingilizler bir taraftan Vahidettin'e vaat ve telkinlerde bulunurken, İstanbul içindeki muhaliflerden yurtdışına kaçmak isteyenler için Trakya'da kaçış merkezleri temini, pasaport sağlanması ve İngiliz Sefaretine sığınanların gemilerle ülke dışına çıkarılması gibi işlerle de uğraşıyorlardi $1^{2}$.

Elde edilen istihbarattan öyle anlaşılıyorki, bu sırada İstanbul Rum Patrikhanesi'nde de son 'gelişmelerden dolayı bir bunalım yaşanmış, Rum Ortodoks Cemaat, Patriklerini, kendilerini uçuruma sürüklediği için suçlamaya başlamışlardı ${ }^{13}$. Yunanistan'da yayınlanan Rum Gazeteleri ise Türkiye'de son alınan kararların eskiden düşünmeye bile cesaret edilemeyecek tarihî adımlar olarak nitelendirilirken bunların ülke içinde mutlaka bir karşı harekete sebeb olacağını da savunuyorlardı ${ }^{14}$.

Artık İstanbul ve belki de memleketin birçok yerinde Vahidettin'in memleket dışına çıkmasının bu meselenin kökünden halli için en az riskli veya en uygun yol olacağı kanaati yerleşmeye başlamıştı. Nitekim, İstanbul gazetelerinden "Yeni Şark"ta. 7 Kasım 1922 tarihinde Vahidettin'in çekilip gitmesi gerektiğine dair bir yazı yayınlanmiştır ${ }^{15}$.

Bu arada iki İngiliz Bölüğü Vahidettin'i korumak amaciyla Saraya yerleştirilirken, 6 Kasım 1922'de İngiliz Sefiri ile Vahidettin'in yaptığı uzun süren ve yanlarına kimseyi almadıkları için neler konuştukları hakkında kesin bilgi verilemeyen görüşmede, muhtemelen Vahidettin'in bundan sonraki durumu ve kaçışı hakkında fikir alışverişinde bulunulduğu zannedilmektedir ${ }^{16}$. Ingilizlerin bu hususta başka bir teşebbüsü de General Harington ile Baş Tercümanı Ryan'ın hazırladıkları ve TBMM'nin Saltanat ve Hilafeti ayırıp, bunlardan saltanatı ilgaya yetkili olmadığını ifade eden bir beyannamedir ${ }^{17}$.

\footnotetext{
11 ATASE Arşiv 1/4283, Kl. 1684. Dos. 39 (436), Fh. 9-11, 17, 17-1

12 a.g.a. 1/4283, Kl. 1684 . Dos. 39 (436), Fh. 17-1, 15, 15-1

13 a.g.a. Fh. $52-2$

14 a.g.a. Fh. 14

15 Gentizon, a.g.e., s. 33

16 a.g.a., Fh. 25, 25-1

17 a.g.a., Fh. 27-1. Felah Grubu raporlarinda bu beyannamenin Harington ve Ryan tarafından hazırlatıldığı ve padișaha imza ettirildiği yazılmaktadır (aynı yer). "Baş Tercüman Mr. Ryan Türkiye'de ençok nefret edilen kimseydi. Amaçları uğrunda hainleri ve alçakları kullanan bir entrikacıydı... Anadolu'ya casuslar gönderen yine oydu" (Bilâl N. ŞIMŞİR, Sakarya'dan İzmir'e, İst. 1972. s. 321).
} 
İstanbul'da bu beyanname'nin hazırlandığına dair gelen yoğun raporlar Ankara'da bazı şahıslarda haklı olarak ciddi rahatsızlık yaratmış ve Fevzi Paşa, Mustafa Kemal Paşa ve Rauf Bey'e bir karşı Beyanname yazılıp gerekli yerlere gönderilmesi teklifini yapmıştır ${ }^{18}$. İngilizlerin faaliyetlerinden rahatsız olan bir başka kişi de İstanbul'daki İstihbarat Teşkilatını yönlendirdiği anlaşılan I. Ordu Kumandanı Nurettin Paşa'dır. Nurettin Paşa bir taraftan İstanbul'un Millî Harekete taraftar ve güvenilir şahıslarına BMM'nin saltanat ve hilafet ile ilgili aldığı kararlara kayıtsız ve şartsız uyacakları ve kabul edecekleri, uygulanması için bütün fedakarlıkları göstereceklerine dair mazbata imzalatırken İstanbul'daki karışı ortamdan İngilizlerin faydalanmasını önlemek için burada daha güçlü bir teşkilat yapılmasını ve kuvvetli bir şahsiyetin bu teşkilatın başına getirilmesini istiyordu ${ }^{19}$.

İşte bu ortamda 11.11.1922'de Vahidettin son "Cuma Selamlığı"na çıkmıştır. Bir kaç kişi haricinde halktan kimsenin katılmadığı, Cuma namazı münasebetiyle hutbelerde hiçbir halife isminin geçmediği Muzika Bölüğü'nün bulunmadığı bir kuru ve ruhsuz mera$\operatorname{sim}^{20}$ gerek İngilizler ve gerekse VI. Mehmet Vahidettin için tam bir hayal kırıklığı olacaktı²1.

Artık Vahidettin'in büyük bir ihtimalle kaçacağı anlaşılmaktadır. Nitekim son "Selamllk Resmi"nden sonra General Harington ve General Pelle'nin saray ile görüşmeleri sıklaşırken ${ }^{22}$, Padişahın firar ettiğine dair çeşitli rivayetler de yapılmaktadır. $\mathrm{Bu}$ rivayetler üzerine Felah Grubu Refet Paşa'ya söylentilere rağmen Padişahın sarayda olduğu ve fakat hazırlıklar yaptığını bildirmiştir ${ }^{23}$.

Nihayet, bilindiği üzere 17.11.1922 de VI. Mehmet Vahidettin hayatını tehlikede gördüğü yolunda bir açıklama yaparak Ingilizlerin himayesini isteyecek ve bu istek kabul edilerek Malaya adlı bir Ingiliz gemisi ile yurt dışına çıkacaktır.

\footnotetext{
18 ATASE Arşiv 1/4283, Kl. 1684, Dos. 39(436), Fh. 27

19 a.g.a. Fh. $25-1,25$

20 a.g.a. Fh. 23. Nitekim hutbe ve muzıka (Nevbet) Türk Devlet Geleneğinde hakimiyet sembolüdür.

21 Gentizon, a.g.e., s. 35; İslam Ansiklopedisi, VI. Mehmet Maddesi, C. 7

22 a.g.a. Fh. 26-1

23 a.g.a. Fh. 16. Bu belgeden anlaşıldığına göre Felah Grubu Padişahın mahremine girecek kadar saray içine de nüfuz etmiştir.
} 